\title{
Neonatal exposure to monosodium glutamate results in dysmorphology of orofacial lower motor neurons
}

\author{
L. Foran ${ }^{1}$, C. Kupelian 1 , S. Laroia², J. Esper², R.J. Kulesza1 \\ ${ }^{1}$ Department of Anatomy, Lake Erie College of Osteopathic Medicine, Erie, PA, United States \\ 2University of Pittsburgh Medical Center - Hamot, Neuroscience Institute, Erie, PA, United States \\ [Received: 16 February 2016; Accepted: 14 March 2016]
}

\begin{abstract}
Glutamate is the most abundant excitatory neurotransmitter in the central nervous system, and is stored and released by both neurons and astrocytes. Despite the important role of glutamate as a neurotransmitter, high levels of extracellular glutamate can result in excitotoxicity and apoptosis. Monosodium glutamate (MSG) is a naturally occurring sodium salt of glutamic acid that is used as a flavour enhancer in many processed foods. Neonatal exposure to MSG has been shown to result in neurodegeneration in several forebrain regions, characterised by neuronal loss and neuroendocrine abnormalities. However, the brainstem effects of neonatal MSG exposure have not been investigated. It is therefore hypothesized that MSG exposure during the early postnatal period would impact brainstem lower motor neurons involved in feeding behaviour. The effect of neonatal MSG exposure on brainstem lower motor neurons was investigated by exposing rat pups to either $4 \mathrm{mg} / \mathrm{g}$ MSG or saline from postnatal day $(P) 4$ through 10. On P28, brains were preserved by vascular perfusion with fixative, frozen sectioned and stained for Niss/ substance. The number, size and shape of brainstem motor neurons were compared between MSG and saline-exposed animals. MSG exposure had no impact on the total number of neurons in the nuclei examined. However, MSG exposure was associated with a significant increase in the number of round somata in both the trigeminal and facial nuclei. Furthermore, MSG exposure resulted in significantly smaller neurons in all motor nuclei examined. These results suggest that neonatal exposure to MSG impacts the development of brainstem lower motor neurons which may impact feeding and swallowing behaviours in young animals. (Folia Morphol 2017; 76, 4: 582-589)
\end{abstract}

Key words: brainstem, facial, trigeminal, hypoglossal, vagus

\section{INTRODUCTION}

Glutamate is the major excitatory neurotransmitter in the central nervous system $[11,33,41]$ and the excitatory effects of glutamate on neurons are well established [7, 20]. Monosodium glutamate (MSG) is a common food additive that dissolves into L-glutamic acid; chronic exposure to MSG is associated with neurotoxic effects $[13,18,43]$. Indeed, administration of high levels of MSG results in persistent activation of glutamate receptors $[12,31]$ and repetitive

Address for correspondence: R.J. Kulesza, Jr., PhD, Department of Anatomy, Lake Erie College of Osteopathic Medicine, 1858 West Grandview Blvd, Erie, PA 16504, United States, tel: 814-866-8423, e-mail: rkulesza@lecom.edu 
and prolonged activation of NMDA receptors results in elevated intracellular $\mathrm{Ca}++$ levels, disruption of mitochondrial membranes, DNA fragmentation and apoptosis [9, 17, 23, 34, 36, 40, 42]. It has been established that the blood-brain barrier of neonates is immature and that glutamate can traverse this barrier and exert excitotoxic effects on adjacent brain regions $[32,42]$. Thus, repeated exposure to MSG, especially during the neonatal period, results in neuronal damage and cell death in a number of different brain regions $[2,4,8,35,38]$. Specifically, MSG exposure has been shown to result in fewer neurons in the spiral ganglion [5], severe degeneration of retinal ganglion cells $[39,47]$, smaller brains and lower body weights [46], fewer cerebellar Purkinje cells, deficits in motor coordination [26, 37] and fewer cortical neurons [6].

Taken together, there is overwhelming evidence that neonatal MSG-exposure causes neuronal degeneration in forebrain and cerebellum. However, the effects of MSG have not been investigated in the brainstem. Orofacial motor circuits are highly functional and active during the neonatal period for suckling, swallowing, blinking and vocalising and are known to receive significant glutamatergic input [45]. It is therefore hypothesized that MSG-induced excitoxicity during the neonatal period might impact structure and function of orofacial lower motor neurons (LMN). To examine this hypothesis, rat pups were exposed to MSG from P4 to $\mathrm{P} 10$ and examined the neuronal morphology in the trigeminal motor nucleus (TMN), facial nucleus (FN), nucleus ambiguous (NA) and the hypoglossal nucleus (HN).

\section{MATERIALS AND METHODS}

All procedures were approved by the Lake Erie College of Osteopathic Medicine Institution Animal Care and Use Committee (protocol \#14-04). Sprague Dawley rats were maintained on a $12 \mathrm{~h}$ light/dark cycle with free access to food and water. Animals were mated and pregnant females were permitted to deliver litters without interference; the date of birth was recorded as postnatal day 0 (PO). On P4, litters were culled to between 6 and 9 male pups; these pups were divided into saline $(n=5)$ and MSG $(n=9)$ injected groups. Between P4 and P10, animals were weighed and injected (subcutaneously, along the dorsal hindquarters) with MSG ( $4 \mathrm{mg} / \mathrm{g}$ ) or saline (equivalent volume of $0.9 \%$ $\mathrm{NaCl})$. This dosage of MSG has been shown previously to produce robust effects in the hippocampus and cerebellum [14, 37]. Litters were weaned at P21 and the two cohorts (saline and MSG) were housed separately.
On P28, animals were weighed and a measurement of total body length (i.e. tip of nose to tip of the tail) was taken. Animals were then anesthetised with an intraperitoneal injection of pentobarbital $(80 \mathrm{mg} / \mathrm{kg})$ and when animals were unresponsive, they were perfused through the ascending aorta with normal saline followed by $4 \%$ paraformaldehyde in $0.1 \mathrm{M}$ sodium phosphate buffer (PB; $\mathrm{pH}$ 7.2; fixative). Brains were dissected from the skull, weighed and the right side of the brainstem was marked with a register pin and brains were stored in fixative (at $4^{\circ} \mathrm{C}$ ) for at least $24 \mathrm{~h}$. Approximately $24 \mathrm{~h}$ before frozen sectioning, brainstems were placed in a solution of $30 \%$ sucrose in fixative at $4^{\circ} \mathrm{C}$ until they were saturated. Brainstems were sectioned on a freesing microtome in the coronal plane at a thickness of $40 \mu \mathrm{m}$. Every third tissue section was collected for histology; these sections were mounted onto glass slides in caudalto-rostral sequence from cresyl gelatin and dried at room temperature. Slides were rehydrated, stained for Nissl substance with Giemsa (Sigma-Aldrich) for $60 \mathrm{~min}$, dehydrated through ascending alcohols, cleared and coverslipped with Permount (Fisher Scientific). Giemsastained tissue sections were examined with an Olympus BX45 microscope. Cell body contours were traced, by an observer blind to experimental condition, using a $40 \times$ objective (final magnification of $1000 \times$ ). Cell body tracings were digitised and quantified using ImageJ (1.48v). For each nucleus, estimates of neuronal number were calculated as previously described [27-29, 48].

\section{Statistical analysis}

Descriptive statistics were generated for all data sets using GraphPad Prism 6 (GraphPad Software).

Correlation between animal body weights and brain weight was examined using Pearson correlation coefficient. All data sets were examined for a normal distribution using the D'Agostino and Pearson omnibus normality test and were compared using parametric tests (i.e. t-test). For each nucleus, a contingency table of cell body morphologies was constructed and the distribution of these morphologies was compared using a $\chi^{2}$ test. Differences were considered statistically significant if $p$ values were $<0.05$.

\section{RESULTS}

\section{Body weight}

Neonatal exposure to MSG was not fatal to any of the exposed animals but resulted in a significant decrease in body weight and shorter head-to-tail length by P28 (Table 1). Additionally, MSG-exposed 
Table 1. Morphometric data

\begin{tabular}{lcc}
\hline & Saline & MSG \\
\hline Survival & $100 \%$ & $100 \%$ \\
Body weight $[\mathrm{g}]$ & $95.26 \pm 15.9$ & $79.41 \pm 9.6^{*}$ \\
Total body length $[\mathrm{cm}]$ & $25.76 \pm 1.2$ & $23.44 \pm 1.38^{* *}$ \\
Brain weight $[\mathrm{g}]$ & $1.52 \pm 0.09$ & $1.42 \pm 0.09^{*}$ \\
\hline
\end{tabular}

Data are shown as mean \pm standard deviation; MSG — monosodium glutamate; ${ }^{*} p<0.05 ;{ }^{* *} p<0.01$

animals had brains that weighted significantly less than saline-exposed animals (Table 1). Correlation of brain weight and body weight revealed $r^{2}$ values of 0.93 (saline) and 0.44 (MSG), suggesting that brain size is not directly proportional to body weight in MSG-exposed animals.

\section{Trigeminal motor nucleus}

In the TMN, neonatal MSG-exposure affected only the distribution of cell body morphologies (Fig. 1). MSG exposure had no impact on the number of neurons in the TMN (Fig. 1C). In saline-exposed animals, the TMN was composed of $67 \%$ stellate ( $\mathrm{S}$; arrowheads in Fig. $1 A$ ), $30 \%$ round ( $R$; arrows) and $4 \%$ fusiform neurons (F; Fig. 1D). In MSG-exposed animals, the TMN was composed of 50\% stellate (arrowheads in Fig. 1B), 40\% round (arrows) and 10\% fusiform neurons and this difference in populations was statistically significant (Fig. 1A, B, D). MSG exposure had no impact on the size of stellate or round neuronal somata in the TMN (Fig. 1E, F).

\section{Facial nucleus}

In the FN, neonatal MSG-exposure resulted in significant dysmorphology of motor neurons (Figs. 2, 3). MSG exposure had no impact on the total number of neurons in the FN (Fig. 2C). In saline-exposed animals, the $\mathrm{FN}$ was composed of $68 \%$ stellate (arrowheads in Fig. $3 \mathrm{~A}$ ), 30\% round (arrows in Fig. $3 \mathrm{~A}$ ) and 2\% fusiform neurons. In MSG-exposed animals, the FN was composed of $43 \%$ stellate (arrowheads in Fig. 3B), $53 \%$ round (arrows in Fig. 3B) and $4 \%$ fusiform neurons (double arrows in Fig. 3B) and this difference in populations was statistically significant (Fig. 2A, B, D). Both stellate and round neuronal somata were significant smaller in MSG exposed animals (Figs. 2E, F; $3 A-D)$. The cross-sectional areas of both stellate and round neuronal somata in saline-exposed animals were normally distributed (Fig. 3C, D). However, in MSG exposed animals, the distribution of both stellate and round neuronal somata were not normally disturbed and were positively skewed (Fig. 3C, D).
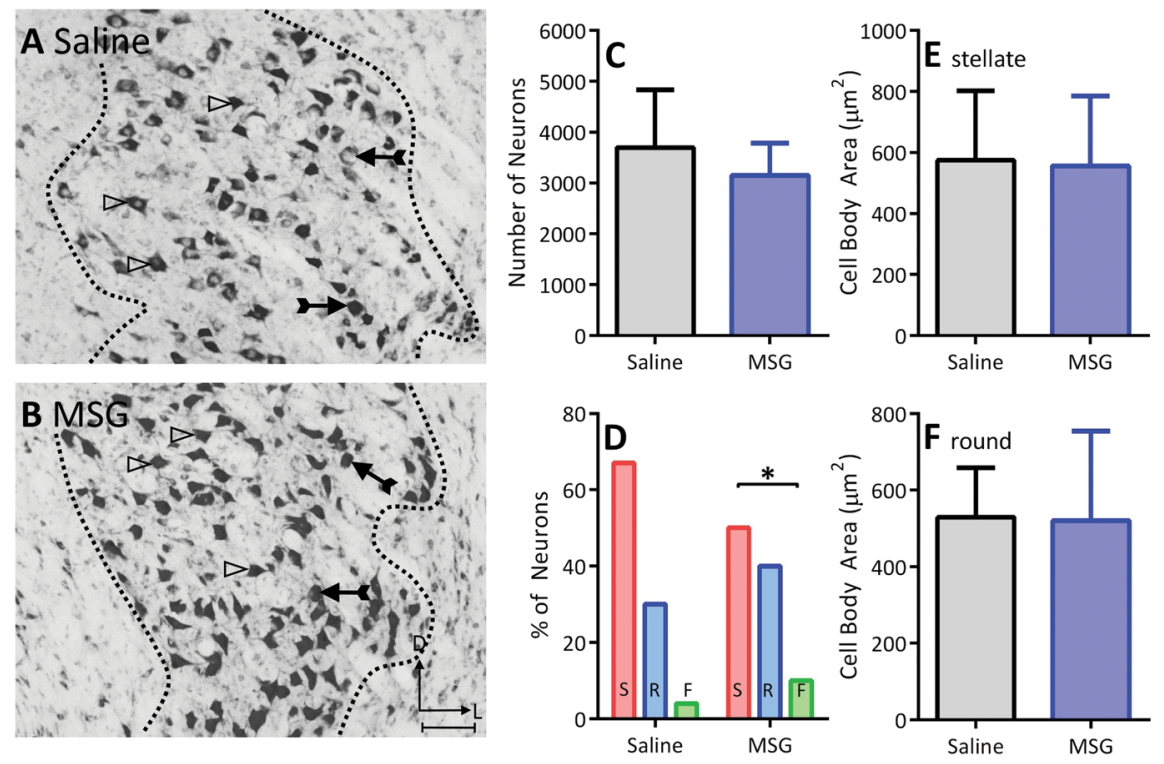

Figure 1. Trigeminal motor nucleus (TMN). Trigeminal motor neurons from saline and monosodium glutamate (MSG)-exposed animals are shown in panels $\mathbf{A}$ and $\mathbf{B}$, respectively (scale bar in panel $\mathbf{B}$ is equal to $100 \mu \mathrm{m}$ ). Arrowheads indicate stellate neurons and black arrows indicate round neurons. The estimated number of TMN neurons is shown in panel $\mathbf{C}$. The distribution of neuronal morphologies is shown in panel $\mathbf{D}$ (Chi square; S - stellate, R - round, F — fusiform). There were fewer stellate neurons and more round neurons in MSG-exposed animals. The cross sectional area of stellate (E) and round (F) TMN neurons is shown. Error bars represent the standard deviation; ${ }^{*} p<0.05$. 

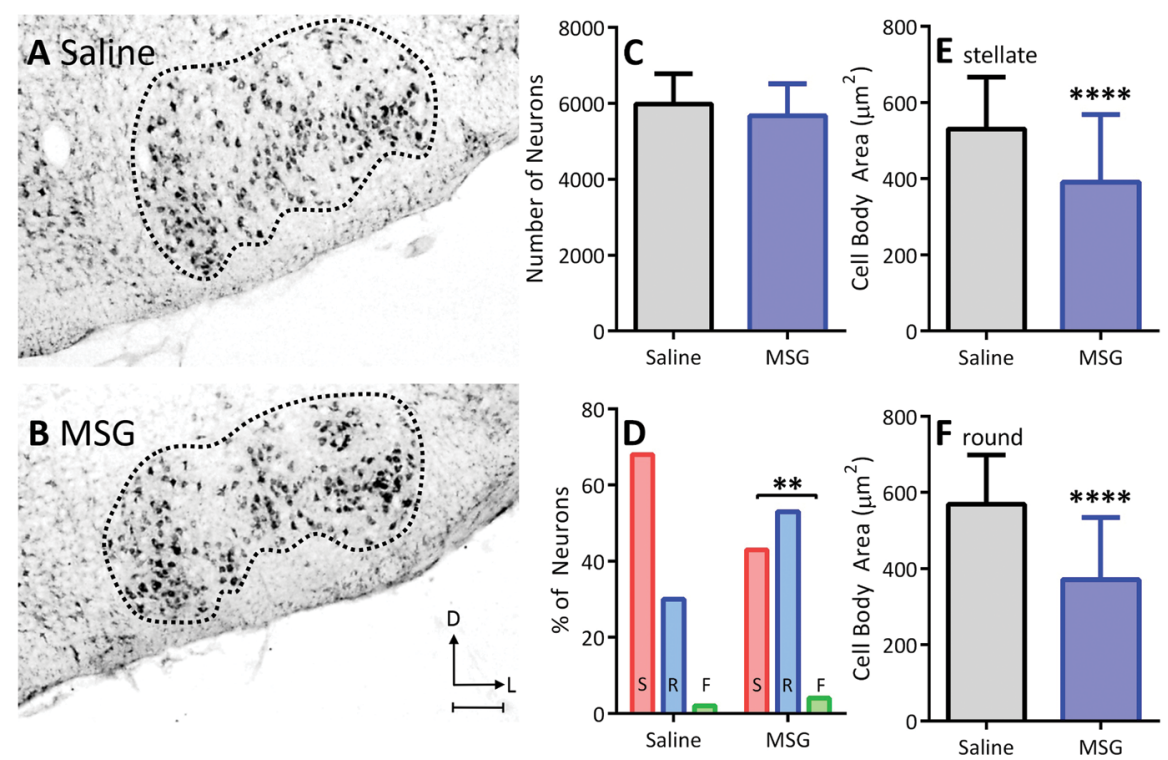

Figure 2. Facial nucleus (FN). The FN is shown from saline (A) and monosodium glutamate (MSG)-exposed animals (B). The scale bar in panel $B$ is equal to $200 \mu \mathrm{m}$. The estimated number of FN neurons is shown in panel $\mathbf{C}$. The distribution of neuronal morphologies is shown in panel D (Chi square; S - stellate, R - round, F - fusiform). There were fewer stellate and more round neurons in MSG-exposed animals. The cross sectional area of stellate $(\mathbf{E})$ and round $(\mathbf{F}) \mathrm{FN}$ neurons is shown. Error bars represent the standard deviation; ${ }^{* *} \mathrm{p}<0.01,{ }^{* * * *} p<0.0001$.
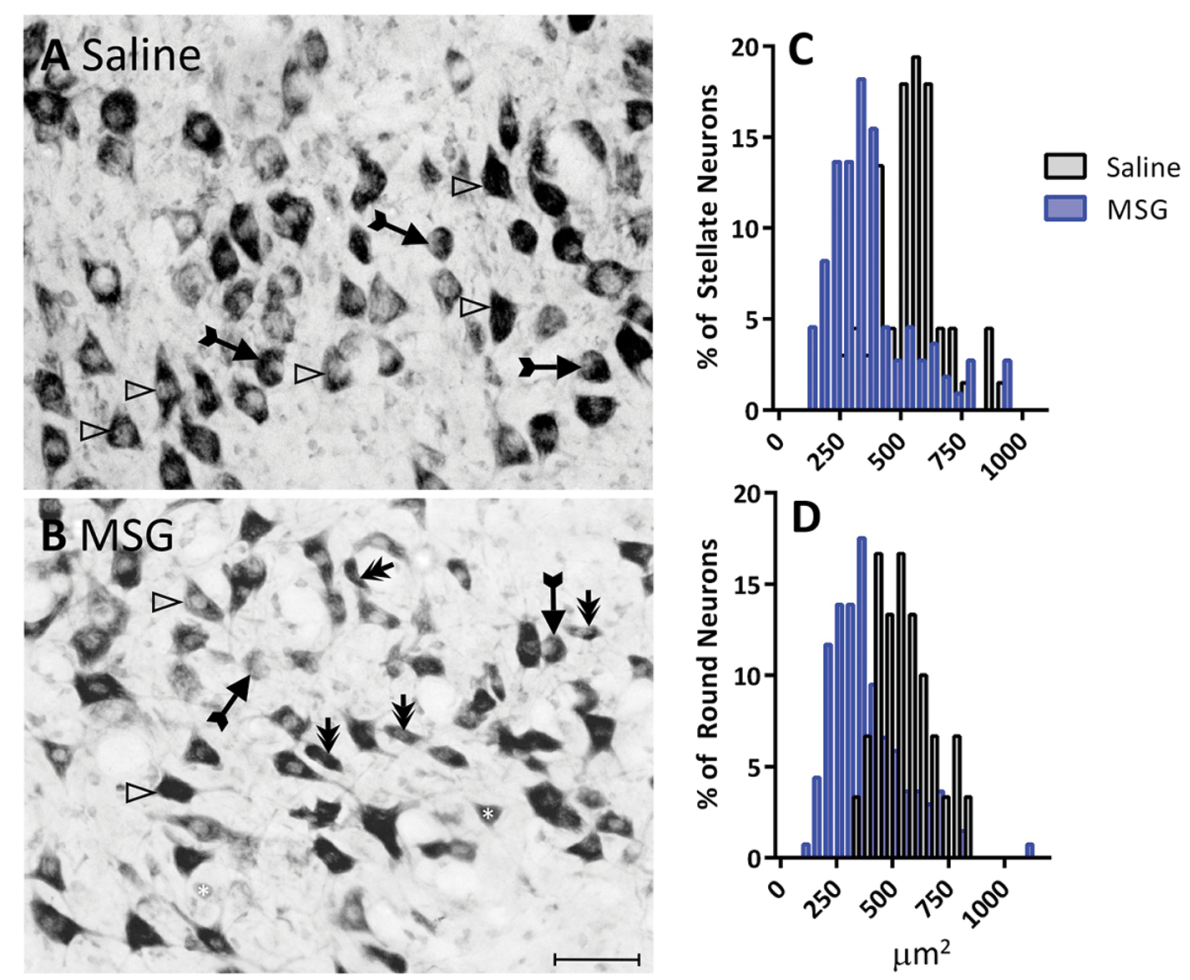

Figure 3. Size of neurons in the facial nucleus (FN). FN neurons from saline (A) and monosodium glutamate (MSG)-exposed (B) animals are shown. In the FN of MSG-exposed animals, both stellate (arrowheads) and round neurons (arrows) had significantly smaller cell bodies, see especially the white asterisks in panel B. Fusiform neurons (double arrows) were more common in MSG-exposed animals. The scale bar in panel B is equal to $60 \mu \mathrm{m}$. In saline-exposed animals, the distribution of both stellate and round neurons followed a normal distribution. In MSG-exposed animals, FN neurons were smaller and the distribution of cell body sizes was skewed (C, D). 

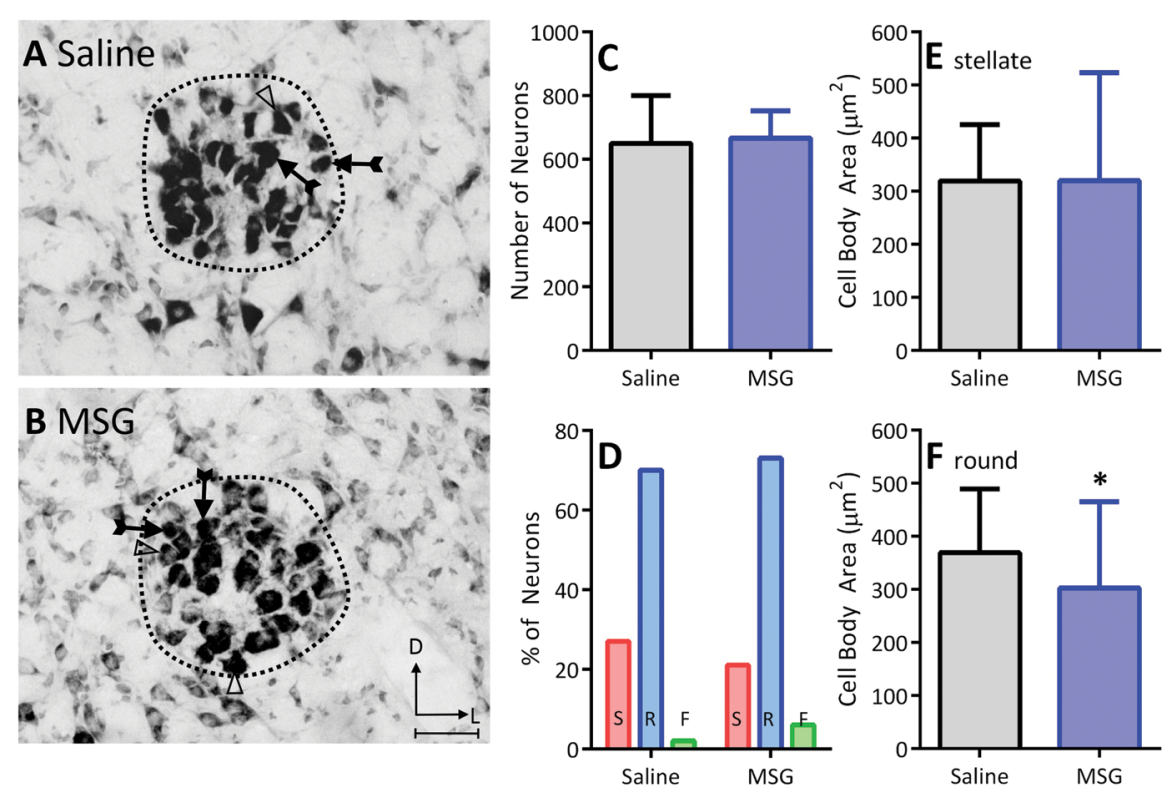

Figure 4. Nucleus ambiguous (NA). NA motor neurons from saline and monosodium glutamate (MSG)-exposed animals are shown in panels $\mathbf{A}$ and $\mathbf{B}$, respectively (the scale bar in panel B is equal to $60 \mu \mathrm{m}$ ). The estimated number of NA neurons is shown in panel $\mathbf{C}$. The distribution of neuronal morphologies is shown in panel $\mathbf{D}$ (Chi square; $\mathbf{S}$ - stellate, $\mathrm{R}$ - round, $\mathrm{F}$ - fusiform). The cross sectional area of stellate (arrowheads; $\mathbf{E}$ ) and round (black arrows; F) NA neurons is shown. Round neurons were significantly smaller in MSG exposed animals. Error bars represent the standard deviation; ${ }^{*} \mathrm{p}<0.05$.

\section{Nucleus ambiguous}

In the NA, neonatal MSG-exposure resulted in only minor dysmorphology of motor neurons with a round morphology (Fig. 4). MSG exposure had no impact on the number of NA neurons (Fig. 4C). In saline-exposed animals, the NA was composed of $27 \%$ stellate (arrowhead in Fig. 4A), 70\% round (arrows in Fig. 4A) and $2 \%$ fusiform neurons. In MSG-exposed animals, the NA was composed of $21 \%$ stellate (arrowheads in Fig. 4B), 73\% round (arrows in Fig. 4B) and $6 \%$ fusiform neurons. There was no difference in the size of stellate neuronal somata in the NA of saline or MSG-exposed animals (Fig. 4E). However, MSG exposure resulted in significantly smaller round NA neuronal somata (Fig. 4F).

\section{Hypoglossal nucleus}

In the HN, neonatal MSG-exposure resulted in dysmorphology of only neurons with round somata (Fig. 5). There was no difference in the number of $\mathrm{HN}$ neurons in saline or MSG-exposed animals (Fig. 5C). In saline-exposed animals, the $\mathrm{HN}$ was composed of $40 \%$ stellate (arrowheads in Fig. $5 \mathrm{~A}$ ), 58\% round (arrows in Fig. 5A) and 2\% fusiform neurons. In MSG-exposed animals, the NA was composed of $25 \%$ stellate (arrowhead in Fig. 5B), 69\% round (arrows in Fig. 5B) and 5\% fusiform neurons. There was no difference in the size of stellate neuronal somata between saline and MSG-exposed animals (Fig. 5E). However, the somata of round neurons in the HN were significantly smaller after MSG exposure (Fig. 5F).

\section{DISCUSSION}

There is abundant evidence that neonatal MSG exposure results in loss of neurons in forebrain regions, the cerebellum, retina and spiral ganglion $[2,4,5$, $8,35,38,39,47]$. Herein, evidence is provided that neonatal MSG exposure also significantly impacts the morphology of orofacial LMNs, with the most severe changes occurring in the FN. This study is based on observations from a small number of MSG-exposed animals $(n=9)$. A more detailed study of a larger cohort of animals will be needed to draw major conclusions. Regardless, gross examination of the brain from the MSG-exposed animals in this study revealed marked atrophy of the optic nerves and tracts. This observation is consistent with previous reports $[39,47]$ and indicates that the dosage scheme used in this study was sufficient to produce forebrain dysmorphology.

The estimates of neuronal number revealed no difference in the number of orofacial LMNs between control and MSG-exposed animals. In other brain regions (e.g. hippocampus), a similar dosing regimen of 

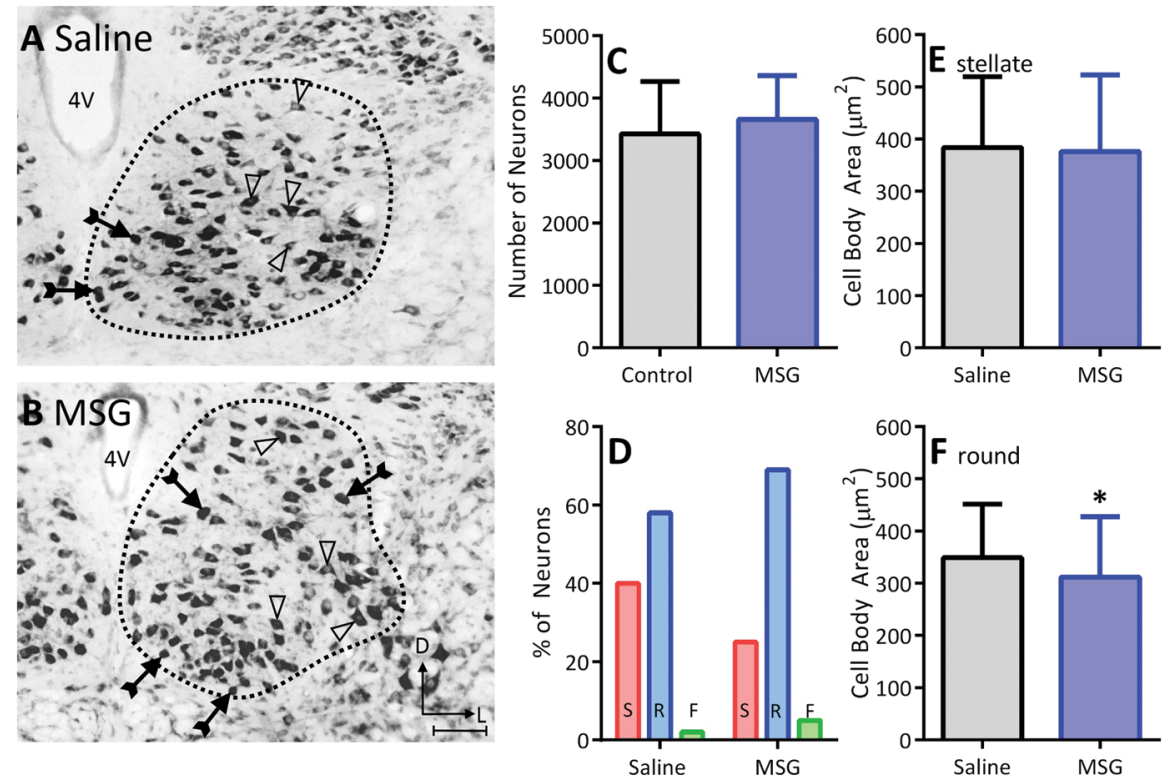

Figure 5. Hypoglossal nucleus (HN). HN motor neurons from saline and monosodium glutamate (MSG)-exposed animals are shown in panels A and B, respectively (the scale bar in panel $B$ is equal to $100 \mu \mathrm{m}$ ). The estimated number of $\mathrm{HN}$ neurons is shown in panel $\mathbf{C}$. The distribution of neuronal morphologies is shown in panel $\mathbf{D}$ (Chi square; $\mathbf{S}$ - stellate, $\mathbf{R}$ - round, $\mathbf{F}$ - fusiform). The cross sectional area of stellate (arrowheads; $\mathbf{E}$ ) and round (black arrows; F) HN neurons is shown. MSG exposure resulted in significantly smaller round neurons in the HN (black arrows; F). Error bars represent the standard deviation; ${ }^{*} p<0.05$.

MSG resulted in significantly fewer neurons [6, 14, 39, 42]. The observation of normal orofacial LMN number suggests these neurons are protected from excitotoxic events in the early neonatal period, as early as $\mathrm{P} 4$. Notably, injury to motor axons between embryonic day 18 and P14 (rat), results in regeneration of injured axons and reinnervation of the muscle [16]. Taken together, these observations suggest that orofacial LMNs might be protected from excitotoxic injury during the neonatal period. Such protection might be contributed by maturation of GABAergic synapses [30], activation of microglia or perineuronal nets [48].

The results provided herein are in accordance with the hypothesis that the number of orofacial LMNs is stable and protected as early as P4 in rats. However, during this early postnatal period, the dendritic arbours are still immature as are the arrangement of excitatory and inhibitory inputs to these neurons. Spinal LMNs have been shown to increase the size of their soma and spread of the dendritic tree, reaching adult morphology by approximately P28 and this process is dependent on activation of NMDA receptors [24]. Brainstem LMNs, like those in the FN, receive input from a number of sources. For example, the FN nucleus is known to receive excitatory inputs from the cerebral cortex, the superior colliculus, red nucleus, reticular formation and a number of addition brainstem centres [15, 22,44,45]. It is proposed that the changes identified in neuronal morphology, especially in the $\mathrm{FN}$, are due to selective sensitivity of neurons providing excitatory input to these LMNs.

There are a large number of excitatory inputs to LMNs in the facial nucleus, such as the periaqueductal grey, red nucleus, superior colliculus, cerebellum and primary motor cortex $[1,10,15,19,21,30]$. Furthermore, excitatory projections from the perioculomotor region and even the oculomotor and Edinger-Westphal nuclei have been demonstrated [15, 19, 30,44]. With the observed retinal degeneration and visual impairment resulting from neonatal MSG exposure [25, 39, 47], it is proposed that ensuing paucity of eye movements might impact the number and strength of excitatory inputs from oculomotor centres and the superior colliculus to facial LMNs. Such an alteration in excitatory inputs might therefore have a significant impact on the morphology of FN somata and dendritic arbours.

\section{CONCLUSIONS}

Evidence is provided that MSG exposure during the neonatal period does not impact the number of 
orofacial LMNs. However, MSG exposure did result in significant smaller neurons in the TMN, FN, NA and HN. Additionally, in both the TMN and FN, significantly more round/oval cell bodies are found after MSG exposure. The data provides evidence that orofacial LMNs are protected from excitotoxic events in the early neonatal period. However, neurons providing excitatory input to these LMNs might be susceptible to MSG. The functional impacts of altered input to LMNs, diminished dendritic arbours or smaller cell bodies is unclear but might result in difficulties in exploration of the animals environment (altered movement of vibrissae), suckling and blinking (facial muscles), chewing (muscles of mastication), swallowing and vocalisation (tongue muscles; pharyngeal and laryngeal muscles). Further investigations into dendritic architecture and feeding behaviours will be necessary to determine the functional impact of these alterations. Even though a small number of animals were examined in this study, the results suggest that neonatal MSG exposure has a significant impact on brainstem neuronal circuits. This result suggests that MSG exposure should be carefully monitored in neonates.

\section{Acknowledgements}

The authors would like to thank the Lake Erie College of Osteopathic Medicine Research Collective. This work was supported by the Lake Erie College of Osteopathic Medicine and the Lake Erie Consortium for Osteopathic Medical Training.

\section{REFERENCES}

1. Alloway KD, Smith JB, Beauchemin KJ. Quantitative analysis of the bilateral brainstem projections from the whisker and forepaw regions in rat primary motor cortex. J Comp Neurol. 2010; 518(22): 4546-4566, doi: 10.1002/ cne.22477, indexed in Pubmed: 20886621.

2. Arees EA, Mayer J. Monosodium glutamate-induced brain lesions: electron microscopic examination. Science. 1970; 170(3957): 549-550, indexed in Pubmed: 5507208.

3. Bojanic VV, Bojanic Z, Najman S, et al. Diltiazem prevention of monosodium glutamate toxicity on hypothalamus in Wistar rats. Arch Oncol. 2004; 12: 19-20.

4. Burde RM, Schainker B, Kayes J. Acute effect of oral and subcutaneous administration of monosodium glutamate on the arcuate nucleus of the hypothalamus in mice and rats. Nature. 1971; 233(5314): 58-60, indexed in Pubmed: 12058742.

5. Carricondo F, Bartolomé MV, Vicente-Torres MA, et al. Sensitivity to glutamate neurotoxicity in different developmental periods of the rat cochlea. Adv Otorhinolaryngol. 2002; 59: 91-95, indexed in Pubmed: 11885666.
6. Chaparro-Huerta V, Rivera-Cervantes MC, Torres-Mendoza $\mathrm{BM}$, et al. Neuronal death and tumor necrosis factor-alpha response to glutamate-induced excitotoxicity in the cerebral cortex of neonatal rats. Neurosci Lett. 2002; 333(2): 95-98, indexed in Pubmed: 12419489.

7. Curtis DR, Phillis JW, Watkin JC. Chemical excitation of spinal neurones. Nature. 1959; 183(4661): 611-613, indexed in Pubmed: 13632811.

8. Everly JL. Light microscopic examination of MSG-induced lesions in the brain of fetal and neonatal rats. Anat Rec. 1971; 169: 312.

9. Fan MMY, Raymond LA. N-methyl-D-aspartate (NMDA) receptor function and excitotoxicity in Huntington's disease. Prog Neurobiol. 2007; 81(5-6): 272-293, doi: 10.1016/j. pneurobio.2006.11.003, indexed in Pubmed: 17188796.

10. Fay RA, Norgren R. Identification of rat brainstem multisynaptic connections to the oral motor nuclei in the rat using pseudorabies virus. II. Facial muscle motor systems. Brain Res Brain Res Rev. 1997; 25(3): 276-290, indexed in Pubmed: 9495559.

11. Fonnum F. Glutamate: a neurotransmitter in mammalian brain. J Neurochem. 1984; 42(1): 1-11, doi: 10.1111/ j.1471-4159.1984.tb09689.x.

12. Gill SS, Mueller RW, McGuire PF, et al. Potential target sites in peripheral tissues for excitatory neurotransmission and excitotoxicity. Toxicol Pathol. 2000; 28(2): 277-284, doi: 10.1177/019262330002800207, indexed in Pubmed: 10805145.

13. Goldsmith PC. Neuroglial responses to elevated glutamate in the medial basal hypothalamus of the infant mouse. J Nutr. 2000; 130(4S Suppl): 1032S-1038S, indexed in Pubmed: 10736376.

14. González-Burgos I, Velázquez-Zamora DA, Beas-Zárate C. Damage and plasticity in adult rat hippocampal trisynaptic circuit neurons after neonatal exposure to glutamate excitotoxicity. Int J Dev Neurosci. 2009; 27(8): 741-745, doi: 10.1016/j.ijdevneu.2009.08.016, indexed in Pubmed: 19733648.

15. Gonzalez-Joekes J, Schreurs BG. Anatomical characterization of a rabbit cerebellar eyeblink premotor pathway using pseudorabies and identification of a local modulatory network in anterior interpositus. J Neurosci. 2012; 32(36): 12472-12487, doi: 10.1523/JNEUROSCI.2088-12.2012, indexed in Pubmed: 22956838.

16. Harris AJ. Critical periods in the development of motoneurons. Rev Neurol (Paris). 1988; 144(11): 643-647, indexed in Pubmed: 3231955.

17. Hartley DM, Choi DW. Delayed rescue of N-methyl-Daspartate receptor-mediated neuronal injury in cortical culture. J Pharmacol Exp Ther. 1989; 250(2): 752-758, indexed in Pubmed: 2569534.

18. Hashem HE, El-Din Safwat MD, Algaidi S. The effect of monosodium glutamate on the cerebellar cortex of male albino rats and the protective role of vitamin C (histological and immunohistochemical study). J Mol Histol. 2012; 43(2): 179-186, doi: 10.1007/s10735-011-9380-0, indexed in Pubmed:22143495.

19. Hattox AM, Priest CA, Keller A. Functional circuitry involved in the regulation of whisker movements. J Comp Neurol. 2002; 442(3): 266-276, indexed in Pubmed: 11774341. 
20. Hayashi T. A physiological study of epileptic seizures following cortical stimulation in animals and its application to human clinics. Jpn J Physiol. 1952; 3: 46-64, doi: 10.2170/ jjphysiol.3.46.

21. Hinrichsen CF, Watson CD. Brain stem projections to the facial nucleus of the rat. Brain Behav Evol. 1983; 22(2-3): 153-163, indexed in Pubmed:6303494.

22. Holstege G, van Ham JJ, Tan J. Afferent projections to the orbicularis oculi motoneuronal cell group. An autoradiographical tracing study in the cat. Brain Res. 1986; 374(2): 306-320, indexed in Pubmed: 3719340.

23. Jung KH, Chu K, Lee ST, et al. Augmentation of nitrite therapy in cerebral ischemia by NMDA receptor inhibition. Biochem Biophys Res Commun. 2009; 378(3): 507-512, doi: 10.1016/j.bbrc.2008.11.081, indexed in Pubmed: 19056343.

24. Kalb RG. Regulation of motor neuron dendrite growth by NMDA receptor activation. Development. 1994; 120(11): 3063-3071, indexed in Pubmed:7720552.

25. Kawamura M, Azuma N, Kohsaka S. [Experimental studies on microphthalmos formation in neonatal rats treated with monosodium-L-glutamate]. Nippon Ganka Gakkai Zasshi. 1989; 93(5): 553-561, indexed in Pubmed: 2801357.

26. Kiss P, Tamas A, Lubics A, et al. Development of neurological reflexes and motor coordination in rats neonatally treated with monosodium glutamate. Neurotox Res. 2005; 8(3-4): 235-244, indexed in Pubmed: 16371318.

27. Kulesza RJ. Cytoarchitecture of the human superior olivary complex: medial and lateral superior olive. Hear Res. 2007; 225(1-2): 80-90, doi: 10.1016/j.heares.2006.12.006, indexed in Pubmed: 17250984.

28. Kulesza RJ. Cytoarchitecture of the human superior olivary complex: nuclei of the trapezoid body and posterior tier. Hear Res. 2008; 241(1-2): 52-63, doi: 10.1016/j. heares.2008.04.010, indexed in Pubmed: 18547760.

29. Kulesza RJ, Lukose R, Stevens LV. Malformation of the human superior olive in autistic spectrum disorders. Brain Res. 2011; 1367: 360-371, doi:10.1016/j.brainres.2010.10.015, indexed in Pubmed: 20946889.

30. Li YQ, Takada M, Kaneko T, et al. Distribution of GABAergic and glycinergic premotor neurons projecting to the facial and hypoglossal nuclei in the rat. J Comp Neurol. 1997; 378(2): 283-294, indexed in Pubmed: 9120066.

31. Mattson MP. Glutamate and neurotrophic factors in neuronal plasticity and disease. Ann N Y Acad Sci. 2008; 1144: 97-112, doi: 10.1196/annals.1418.005, indexed in Pubmed: 19076369.

32. McCall A, Glaeser BS, Millington W, et al. Monosodium glutamate neurotoxicity, hyperosmolarity, and bloodbrain barrier dysfunction. Neurobehav Toxicol. 1979; 1(4): 279-283, indexed in Pubmed: 121936.

33. Michaelis EK. Molecular biology of glutamate receptors in the central nervous system and their role in excitotoxicity, oxidative stress and aging. Prog Neurobiol. 1998; 54(4): 369-415, indexed in Pubmed: 9522394.

34. Ndountse LT, Chan HM. Role of N-methyl-D-aspartate receptors in polychlorinated biphenyl mediated neurotoxicity. Toxicol Lett. 2009; 184(1): 50-55, doi: 10.1016/j. toxlet.2008.10.013, indexed in Pubmed: 19022367.
35. Oser BL, Carson S, Vogin EE, et al. Oral and subcutaneous administration of monosodium glutamate to infant rodents and dogs. Nature. 1971; 229(5284): 411-413, indexed in Pubmed: 4926993.

36. Patel M, Day BJ, Crapo JD, et al. Requirement for superoxide in excitotoxic cell death. Neuron. 1996; 16(2): 345-355, indexed in Pubmed: 8789949.

37. Prastiwi D, Djunaidi A, Partadiredja G. High dosage of monosodium glutamate causes deficits of the motor coordination and the number of cerebellar Purkinje cells of rats. Hum Exp Toxicol. 2015; 34(11): 11711179, doi: 10.1177/0960327115572706, indexed in Pubmed: 25697849.

38. Quines CB, Rosa SG, Da Rocha JT, et al. Monosodium glutamate, a food additive, induces depressive-like and anxiogenic-like behaviors in young rats. Life Sci. 2014; 107(1-2): 27-31, doi: 10.1016/j.Ifs.2014.04.032, indexed in Pubmed: 24802127.

39. Regan JW, Roeske WR, Ruth WH, et al. Reductions in retinal gamma-aminobutyric acid (GABA) content and in [3H]flunitrazepam binding after postnatal monosodium glutamate injections in rats. J Pharmacol Exp Ther. 1981; 218(3): 791-796, indexed in Pubmed: 6267248.

40. Rivera-Cervantes MC, Torres JS, Feria-Velasco A, et al. NMDA and AMPA receptor expression and cortical neuronal death are associated with p38 in glutamate-induced excitotoxicity in vivo. J Neurosci Res. 2004; 76(5): 678-687, doi: 10.1002/jnr.20103, indexed in Pubmed: 15139026.

41. Robinson MB, Coyle JT. Glutamate and related acidic excitatory neurotransmitters: from basic science to clinical application. FASEB J. 1987; 1(6): 446-455, indexed in Pubmed: 2890549.

42. Shah SA, Yoon GHo, Kim HO, et al. Vitamin C neuroprotection against dose-dependent glutamate-induced neurodegeneration in the postnatal brain. Neurochem Res. 2015; 40(5): 875-884, doi: 10.1007/s1 1064-015-1540-2, indexed in Pubmed: 25701025.

43. Stafstrom CE. The role of glutamate transporters in developmental epilepsy: a concept in flux. Epilepsy Curr. 2004; 4(6): 243-244, doi: 10.1111/j.1535-7597.2004.46009.x, indexed in Pubmed: 16059514.

44. Takada M, Itoh K, Yasui Y, et al. Distribution of premotor neurons for orbicularis oculi motoneurons in the cat, with particular reference to possible pathways for blink reflex. Neurosci Lett. 1984; 50(1-3): 251-255, indexed in Pubmed: 6493629.

45. Travers JB. Oromotor Nuclei. In: George Paxinos, Oromotor Nuclei. Academic Press 2015: 223-245.

46. Ureña-Guerrero ME, López-Pérez SJ, Beas-Zárate C. Neonatal monosodium glutamate treatment modifies glutamic acid decarboxylase activity during rat brain postnatal development. Neurochem Int. 2003; 42(4): 269-276, indexed in Pubmed: 12470699.

47. van Rijn CM, Marani E, Rietveld WJ. The neurotoxic effect of monosodium glutamate (MSG) on the retinal ganglion cells of the albino rat. Histol Histopathol. 1986; 1(3): 291-295, indexed in Pubmed: 2980121.

48. Wagoner JL, Kulesza RJ. Topographical and cellular distribution of perineuronal nets in the human cochlear nucleus. Hear Res. 2009; 254(1-2): 42-53, doi: 10.1016/j. heares.2009.04.008, indexed in Pubmed: 19383535. 